\title{
Postoperative Adhesion Prevention with a New Barrier: An Experimental Study
}

\author{
M. Ditzel ${ }^{\mathrm{a}} \quad$ E.B. Deerenberg ${ }^{\mathrm{a}} \quad$ N. Komen ${ }^{\mathrm{c}} \quad$ I.M. Mulder ${ }^{\mathrm{a}} \quad$ H. Jeekel ${ }^{\mathrm{b}} \quad$ J.F. Lange ${ }^{\mathrm{a}}$ \\ Departments of a Surgery and ${ }^{\mathrm{b}}$ Neuroscience, Erasmus MC, University Medical Center Rotterdam, \\ Rotterdam, The Netherlands; ' ${ }^{\mathrm{D}}$ Department of Surgery, University Hospital Antwerp, Edegem, Belgium
}

\section{Key Words}

Abdominal adhesion prevention - Barrier - Experimental animal model $\cdot$ Side-wall defect model $\cdot$ A-Part ${ }^{\circledR}$ gel $\cdot$ Adept $^{\circledR}$

\begin{abstract}
Introduction: Postoperative adhesion formation remains a major clinical problem. The aim of this study was to test the effect of a new hydrogel on adhesion formation in a rat model. Materials and Methods: A reproducible rat model was used to induce standardized adhesion formation in three experiments. In experiment 1, a cross-linked polyvinyl alcohol (PVA) and carboxymethylcellulose (CMC) hydrogel (PVA/ CMC, A-Part ${ }^{\circledR} ;$ B. Braun Aesculap, Germany) was tested in different dosages. In experiment 2, PVA/CMC gel was compared to icodextrin $4 \%$ (Adept ${ }^{\circledR} ;$ Baxter USA). In both groups, animals were sacrificed after 2 weeks. In experiment 3 , histological examination after 4 and 6 weeks was performed. The percentage of adhesions to the defect was measured and the density was determined according to the Zühlke scale. During histological examination of the abdominal wall, the formation of neoperitoneum and potential residues of the agents were assessed. Results: In experiment 1, a significant reduction in amount as well as density of the adhesions was visible with all dosages of PVA/CMC gel. In experi-
\end{abstract}

ment 2, again quantity and density of the adhesions were diminished by PVA/CMC hydrogel compared to the control group. Icodextrin $4 \%$ showed no significant reduction in adhesion formation. In experiment 3 , no residues of PVA/CMC gel or icodextrin $4 \%$ were found during histological examination after 4 and 6 weeks and neoperitoneum was present in all cases. Conclusion: PVA/CMC hydrogel appears to be a novel effective adhesion prevention agent. Together with an upcoming safety study, these data encourage to start clinical efficacy studies.

Copyright $\odot 2012$ S. Karger AG, Basel

\section{Introduction}

Postoperative peritoneal adhesions remain a major clinical problem with an incidence up to $95 \%$ after abdominal surgery [1]. The most severe complication is small bowel obstruction which is caused by adhesions in $60-70 \%$ of all cases [2]. Other complications include infertility, chronic pain and more difficult access at reoperation. Parker et al. [3] showed the clinical impact of these problems in the SCAR1 study. They established that $32.6 \%$ of all patients after open lower abdominal surgery were readmitted to the hospital with adhesion-related problems within 10 years. The impact of this readmission

\section{KARGER}

Fax +4161306 1234

E-Mail karger@karger.ch

www.karger.com
(C) 2012 S. Karger AG, Basel

0014-312X/12/0484-0187\$38.00/0

Accessible online at:

www.karger.com/esr
Max Ditzel

Dr. Molewaterplein 50

NL-3015 GE Rotterdam (The Netherlands)

Tel. +31 107043683

E-Mailm.ditzel@erasmusmc.nl 
rate is represented by a major economic burden of adhesions on healthcare, emphasizing the importance of a low-cost and effective adhesion prevention modality $[4,5]$.

In recent years, many studies have been performed in an attempt to find an effective adhesion prevention method following abdominal operations. These methods include pharmacological agents, site-specific physical barriers and broad-coverage physical barriers. The barriers have in common that a temporary chemical interface prevents adhesions to develop between the parietal peritoneal defect and the visceral peritoneum. Unfortunately, despite all efforts, no product has been adopted for general clinical use in abdominal surgery [6]. The physically cross-linked polyvinyl alcohol (PVA) and carboxymethylcellulose (CMC) (PVA/CMC, A-Part ${ }^{\circledR}$; B. Braun Aesculap, AG, Tuttlingen, Germany) hydrogel is a new physical barrier which can be applied at the end of the operation on the viscera. In few earlier animal studies with this gel a significant adhesion reduction effect was found; however, more data were necessary to confirm the antiadhesive properties of this product [7-9]. In the present study, PVA/ CMC gel is compared to icodextrin $4 \%$ (Adept $^{\circledR}$; Baxter USA), which is one of the most used antiadhesive agents in abdominal surgery with level I evidence for an antiadhesive effect following gynecological operations [10].

The aim of this study was to test the effect of PVA/ CMC hydrogel on adhesion formation in a rat model.

\section{Materials and Methods}

\section{Study Design}

A reproducible rat model was used to investigate adhesion formation. 106 WAG/Rij rats were assigned to nine different groups: 14 animals per group in experiment 1 and 10 animals per group in experiments 2 and 3 . In each group a standardized peritoneal trauma was created and with exception of the control group an antiadhesive agent was applied. After 2 weeks the animals were humanely sacrificed and adhesions were scored on quantity and severity. The animals in experiment 3 were sacrificed after 4 and 6 weeks

\section{Animals}

Female WAG/Rij rats weighing 125-175 g with an age of 9-11 weeks were obtained from a licensed breeder and accustomed to laboratory conditions for 2 weeks before the start of the experiment. The animals were kept under standard laboratory conditions (temperature $20-24^{\circ} \mathrm{C}$; relative humidity $50-60 \%$; $12 \mathrm{~h}$ light and $12 \mathrm{~h}$ dark cycles) and had free access to water and standard rat food during the whole experimental period. The protocol of the experiment was approved by the Animal Experiments Committee of the Erasmus University Rotterdam.
PVA/CMC Hydrogel

A-Part ${ }^{\circledR}$ gel consists of PVA and CMC (A-Part ${ }^{\circledR}$; B. Braun Aesculap). PVA is the antiadhesion component while $\mathrm{CMC}$ promotes attachment at the wound side. The gel acts like a physical barrier and is applied at the end of the operation. PVA/CMC gel is completely absorbed in 3-4 weeks and its main route of excretion is via the urine.

\section{Icodextrin}

Icodextrin $4 \%$ (Adept $^{\circledR}$; Baxter USA) is a high-molecularweight $\alpha 1,4$-glucose polymer solution. It is metabolized by $\alpha$-amylase to oligosaccharides, but since amylase is absent in the peritoneal cavity, icodextrin $4 \%$ has a prolonged absorption time up to 3-5 days. Finally, absorption occurs via lymphatic drainage into the systemic system. The working principle is based on hydroflotation, which means that damaged surfaces physically are separated during the critical period for adhesion formation [11, $12]$.

\section{Adhesion Experiment 1}

The aim of experiment 1 was to find the ideal dose of PVA/ $\mathrm{CMC}$ gel in our rat model. All experiments were performed under aseptic conditions, 56 animals were operated. At the beginning of each experiment, animals were anesthetized by inhalation of an isoflurane-oxygen mixture. The abdomen was shaved and cleaned with alcohol 70\%. A skin incision of $4 \mathrm{~cm}$ in the midline was made, followed by a $3-\mathrm{cm}$ incision through the linea alba to open the abdominal cavity. Subsequently, on both lateral sides of the abdominal wall, an area of $20 \times 5 \mathrm{~mm}$ of parietal peritoneum was excised including the superficial part of the underlying musculature. The wound was closed using three absorbable sutures (5-0 polyglycolic acid). All knots were double and fastened tightly to ensure local ischemia. At the end of the procedure, PVA/CMC gel was applied equally on both sides in different quantities per group. In group 1, 14 animals received $1.2 \mathrm{ml}$ gel, group 2, $0.8 \mathrm{ml}$ gel, group 3, $0.4 \mathrm{ml}$ gel, and group 4 was the control group without PVA/CMC. After this procedure the abdomen and skin were both closed with a running absorbable suture (5-0 polyglycolic acid).

\section{Adhesion Experiment 2}

The purpose of experiment 2 was to compare the ideal dose of PVA/CMC gel from the first experiment to icodextrin $4 \%$. The same procedure as in experiment 1 was followed and a parietal defect was created and closed in 30 animals. One group received $5 \mathrm{ml}$ icodextrin 4\%, in another, $0.4 \mathrm{ml} \mathrm{PVA} / \mathrm{CMC}$ hydrogel was applied and in the control group again no agent was used. To prevent leakage of icodextrin $4 \%$, the abdomen was in addition to suturing sealed with tissue glue (Dermabond; Johnson \& Johnson, Somerville, N.J., USA).

\section{Adhesion Experiment 3}

In this experiment, 20 animals were operated following the same procedure as in the earlier two experiments applying $0.4 \mathrm{ml}$ PVA/CMC gel in one group of 10 animals and icodextrin $4 \%$ in the others. The objective was to investigate if remnants of the antiadhesives were microscopically visible in the abdominal wall after a longer period. Animals were sacrificed after 4 and 6 weeks and samples of the abdominal wall were taken for histological examination. 
Measurements

\section{Adhesion Formation}

After 2 weeks the animals were anesthetized and the abdomen was opened by an incision through the midline. Two independent observers who were blinded for all groups scored adhesion formation macroscopically using a standardized scoring system. The previously created peritoneal wound was divided in eight segments by the three sutures and adhesions attached to one segment were scored as $12.5 \%$ of the total wound surface. Total adhesion formation was the sum of all areas to which adhesions were attached with a maximum of $100 \%$. Two lateral peritoneal sides were assessed in each rat.

For objective scoring of the severity of the adhesions the Zühlke scoring system was used [13]. This system has a four-degree classification of adhesions based on histological and morphological criteria (table 1). Finally the animals were sacrificed by cardiac incision.

\section{Pictures}

Photographs were taken of all procedures during the experiment with a 5.0-megapixel digital camera (Sony Cybershot).

\section{Histology}

After scoring, the adhesions' transverse sections of the wound area including underlying musculature were fixed in $10 \%$ neutral-buffered formalin for $24 \mathrm{~h}$. After routine tissue processing, sections were cut at 4-6 $\mu \mathrm{m}$ and stained with hematoxylin and eosin. The formation of neoperitoneum was assessed by microscopic examination of the sections. In addition, we investigated whether the adhesion barriers were completely absorbed or had any remains in the abdominal wall. The grade of inflammation was assessed using a semiquantitative scoring system, the inflammation grading scale. Grade 1 on this scale represents a mild inflammatory reaction with giant cells, occasional scattered lymphocytes, and plasma cells, grade 2 represents a moderate reaction with giant cells and increased admixed lymphocytes, plasma cells, eosinophils and neutrophils, and grade 3 represents a severe inflammatory reaction with microabscesses present [14].

\section{Statistical Analysis}

The Shapiro-Wilk test was used to confirm normal distribution of the data; percentage adhesion formation and Zühlke score is presented in mean values with standard deviations. The groups were compared using $\chi^{2}$, one-way ANOVA testing and post-hoc Dunnett tests. All data were two-sided tested and reported $\mathrm{p}$ values are considered significant if $<0.05$. Statistical analysis was performed using PSAW statistical software package, version 17 (IBM SPSS statistics).

\section{Results}

No wound infection, bowel obstruction or peritonitis was observed and all groups were comparable for weight during the experiments. One animal in the 1.2-ml PVA/ $\mathrm{CMC}$ group died within $24 \mathrm{~h}$ of the initial operation. Necropsy showed no intra-abdominal cause of death.

Postoperative Adhesion Prevention with a New Barrier

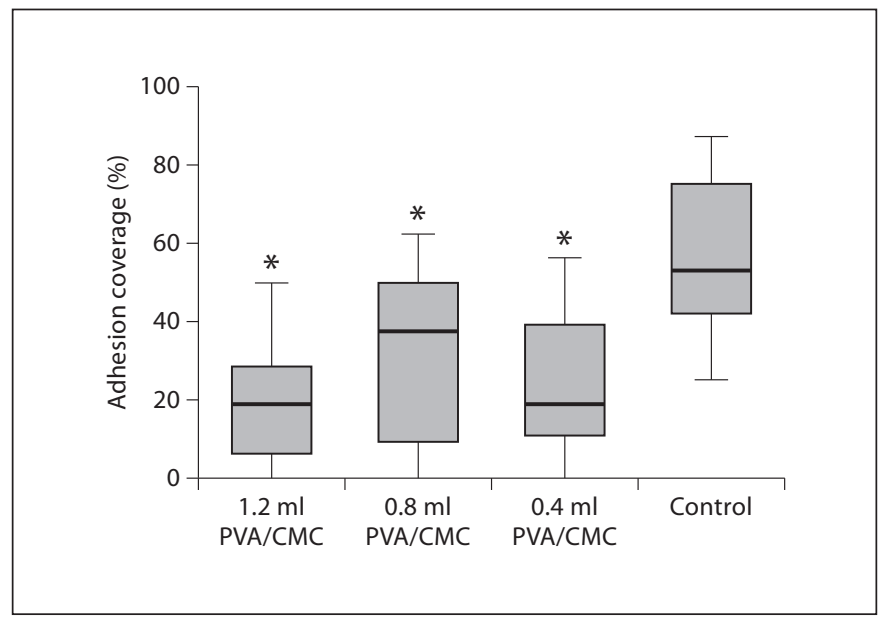

Fig. 1. Experiment 1, dose finding: percentage of the abdominal wall defect covered with adhesions compared to the control group (one-way ANOVA).

Table 1. Zühlke score: macroscopic classification of abdominal adhesions

\begin{tabular}{ll}
\hline Zühlke type & Characteristics \\
\hline 1 & $\begin{array}{l}\text { Filmy adhesion, easy to separate by blunt dis- } \\
\text { section }\end{array}$ \\
\hline 2 & $\begin{array}{l}\text { Stronger adhesion; blunt dissection possible, } \\
\text { partly sharp dissection necessary; beginning of } \\
\text { vascularization }\end{array}$ \\
\hline 3 & $\begin{array}{l}\text { Stronger adhesion; lysis possible by sharp dis- } \\
\text { section only; clear vascularization }\end{array}$ \\
\hline 4 & $\begin{array}{l}\text { Very strong adhesion; lysis possible by sharp } \\
\text { dissection only; organs strongly attached with } \\
\text { severe adhesions; damage of organs hardly pre- } \\
\text { ventable }\end{array}$ \\
\end{tabular}

\section{Experiment 1}

All animals in the PVA/CMC gel groups showed a significant reduction in adhesion formation compared to the control group. The mean coverage of the abdominal wall defect in the 1.2-ml group was 18.3\% (SD 14.5, p < 0.001 ), in the $0.8-\mathrm{ml}$ group $32.1 \%$ (SD 21.7, p < 0.006), after $0.4 \mathrm{ml} \mathrm{21.1 \%} \mathrm{(SD} \mathrm{19.0,} \mathrm{p}<0.001$ ) and in the control group 54.9\% (SD 18.3) (fig. 1). Since every animal has two defects, the total number of defects per group was 28 . In the 1.2-ml PVA/CMC group the number of defects without any adhesion was 9 out of $26(34.6 \%)$, in the $0.8-\mathrm{ml}$ 


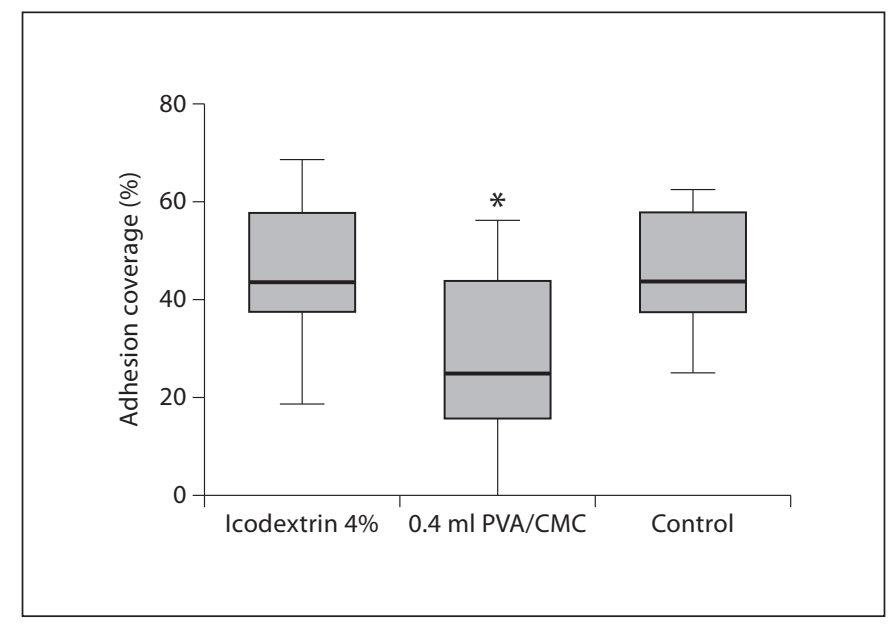

Fig. 2. Experiment 2, A-Part compared to Adept: percentage of the abdominal wall defect covered with adhesions compared to the control group (one-way ANOVA).

Table 2. Experiment 1, dose finding: number of defects without adhesions per group compared to control ( $\chi^{2}$ test)

\begin{tabular}{llcl}
\hline Group & $\begin{array}{l}\text { PVA/CMC } \\
\text { gel }\end{array}$ & $\begin{array}{l}\text { Defects without } \\
\text { adhesions, } \mathrm{n}\end{array}$ & p value \\
\hline 1 & $1.2 \mathrm{ml}$ & $9(34.6 \%)$ & 0.018 \\
2 & $0.8 \mathrm{ml}$ & $10(35.7 \%)$ & 0.020 \\
3 & $0.4 \mathrm{ml}$ & $9(32.1 \%)$ & 0.040 \\
4 & control & $2(7.1 \%)$ & - \\
\hline
\end{tabular}

Table 3. Experiment 1, dose finding: the mean Zühlke score compared to the control group (Mann-Whitney test, Kruskal-Wallis)

\begin{tabular}{llll}
\hline Group & \multicolumn{3}{l}{ Dose finding: Zühlke score } \\
\cline { 2 - 4 } & A-Part ${ }^{\circledR}$ & mean Zühlke & p value \\
\hline 1 & $1.2 \mathrm{ml}$ & 0.73 & $<0.001$ \\
2 & $0.8 \mathrm{ml}$ & 0.93 & 0.029 \\
3 & $0.4 \mathrm{ml}$ & 0.79 & 0.001 \\
4 & control & 1.46 & - \\
\hline
\end{tabular}

group, 10 out 28 (35.7\%) and in the $0.4-\mathrm{ml}$ group, 9 out of $28(32.1 \%)$. In the control group, 2 out of 28 (7.1\%) defects had no adhesion coverage (table 2). Tenacity of adhesions was significantly reduced in all PVA/CMC gel groups (table 3).

\section{Experiment 2}

In the PVA/CMC gel group, a significant adhesion reduction of $42.5 \%$ was found compared to the control group. In contrast, the icodextrin $4 \%$ group did not show any significant adhesion reduction. Mean adhesion coverage was in the A-Part group 26.5\%, icodextrin $45.6 \%$ and the control $45.6 \%$ (PVA/CMS vs. control, $\mathrm{p}=$ 0.017 , icodextrin vs. control, $\mathrm{p}=0.925$, PVA/CMC vs. icodextrin, $\mathrm{p}=0.027)$. In the icodextrin group, 2 out of $20(10 \%)$ defects, in the PVA/CMC group, 7 out of 20 (35\%) defects, and in the control group, 0 out of $20(0 \%)$ defects without adhesions were noted (PVA/CMC vs. control, $\mathrm{p}=0.008$, PVA/CMC vs. icodextrin, $\mathrm{p}=0.127$, icodextrin vs. control, $\mathrm{p}=0.487$ ). Adhesion coverage is shown in figure 2.

The Zühlke score was significantly reduced in the PVA/CMC gel group (Zühlke 0.65, p = 0.032) compared to the control group (Zühlke 1.05). Increasing of the Zühlke score in the icodextrin $4 \%$ group was without significance (Zühlke 1.3, $\mathrm{p}=0.213$ ).

In the control and icodextrin $4 \%$ groups, histological examination of the abdominal wall after 2 weeks showed an inflammatory reaction grade 1 . In addition, a small layer of new mesothelial cells was visible in all cases. In the PVA/CMC group, remains of the gel were still visible after 2 weeks combined with an inflammatory reaction grade 2 (fig. 3). For comparison, an example of a histology sample of the control group is shown in figure 4 . No icodextrin $4 \%$ was found in any of the histological samples.

\section{Experiment 3}

Histological examination of the abdominal wall after 4 as well as after 6 weeks revealed the formation of neoperitoneum in all cases. An inflammatory reaction grade 1 was still visible in all animals, although more prominent in the 4-week than in the 6-week samples. After meticulous microscopic examination, no PVA/CMC gel or icodextrin $4 \%$ residues were visible in any sample after 4 and 6 weeks.

\section{Discussion}

Postoperative adhesion formation is the result of disturbed healing of the peritoneum after surgical trauma, infection or ischemia. Hereby an inflammatory reaction is induced, resulting in migration of neutrophils, macrophages and leukocytes to the site of the trauma. In combination with simultaneous activation of resident meso- 


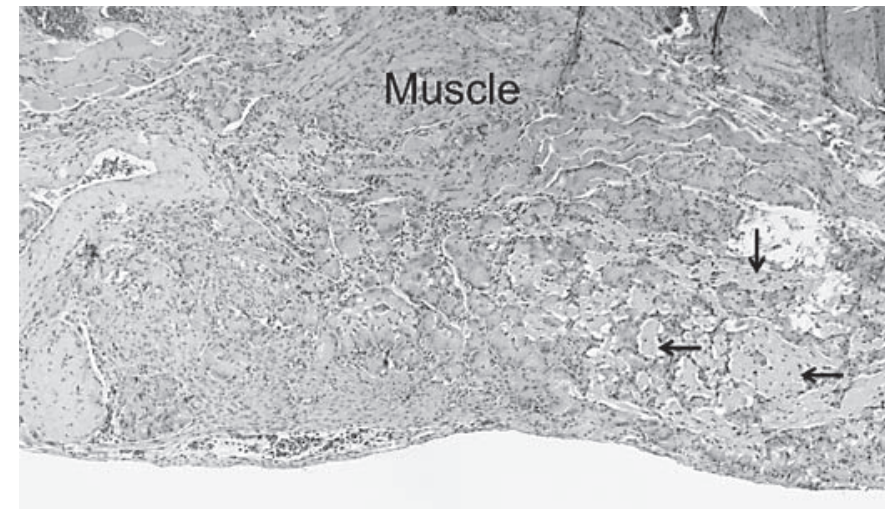

Abdomen

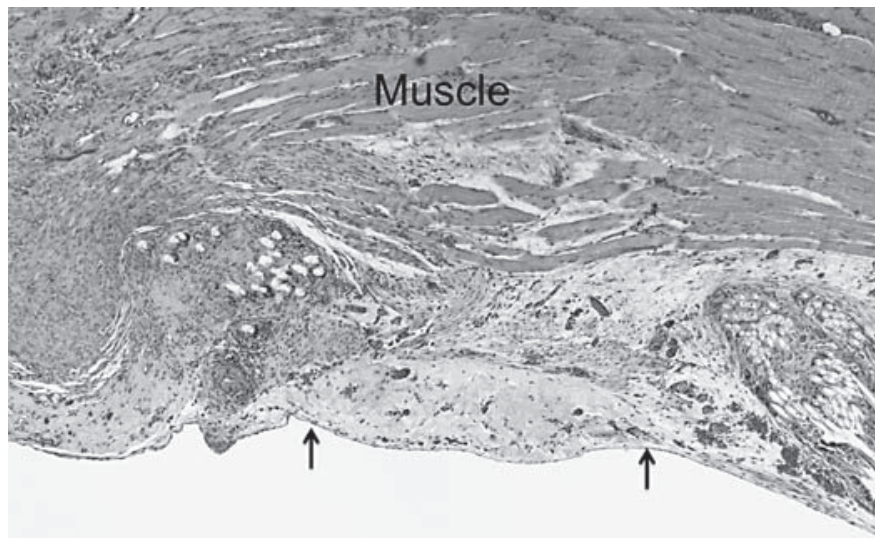

Abdomen
Fig. 3. Experiment 2, PVA/CMC compared to icodextrin: histological examination $(100 \times)$ of the abdominal wall after 2 weeks. PVA/CMC gel residues were present (black arrows). thelial cells, which produce cellular mediators encouraging the migration process, a fibrinous exudate is formed. Whether this exudate will lead to adhesion formation depends on the fibrinolytic capacity in the peritoneal cavity $[15,16]$. Severity and extent of surgical trauma are important factors influencing this formation.

In addition to surgical trauma caused by instruments, Luijendijk et al. [17] found that foreign materials such as glove powder and sutures also induce adhesion formation. Therefore, surgeons should be aiming for meticulous surgery and minimal contamination with foreign materials of the abdominal area. However, such methods only diminish and certainly do not prevent adhesion formation completely. Additionally, use of an adhesion reduction agent might be essential.

Adhesion reduction agents can generally be divided in pharmacological agents, site-specific physical barriers and broad-coverage physical barriers. Potential pharmacological agents like fibrinolytics, steroids and NSAIDs were shown to be effective in experimental studies, but no clinical studies have shown adhesion reduction benefits and these compounds may be associated with side effects like abdominal hemorrhage and impaired wound healing $[15,18,19]$. In contrast, several physical barriers are approved and available on the market as adhesion reduction agents. Nevertheless, their success in safety, costs and effectiveness vary $[18,20-25]$. A recent study revealed the results of 10-year follow-up after Hartmann's procedure and the use of Seprafilm. It was shown that
Fig. 4. Experiment 2, PVA/CMC compared to icodextrin 4\%, control group: histological examination of the abdominal wall after 2 weeks. A new mesothelial layer is visible on the abdominal side (black arrows).

Seprafilm did not protect against small-bowel obstruction, but the incidence of chronic abdominal complaints was significantly lower compared with controls [26]. One of the currently used barriers, icodextrin $4 \%$, is a broadcoverage agent working on the principle of separating damaged surfaces by hydroflotation. In several studies involving gynecological surgery, icodextrin $4 \%$ has been proven to be effective and in the first double-blind RCT for an adhesion reduction agent a significant favorable effect was found [10]. Nonetheless, other authors stated that evidence is far from conclusive and further studies are awaited [27].

In order to find an effective and feasible adhesion prevention agent, a new adhesion prevention barrier based on PVA was developed [7]. The results were very promising; however, the gel appeared to slip away from the trauma site too easily. To improve the quality of adherence to the abdominal wall, CMC was added resulting in PVA/CMC gel [9]. In the first experimental studies the new hydrogel seemed to be a feasible and effective adhesion prevention agent, although still few data are available [7-9].

In experiment 1 , the efficacy of the new adhesion prevention gel was evaluated in different dosages, resulting in a significant reduction of amount and severity of adhesions in all PVA/CMC gel groups. One animal died within $24 \mathrm{~h}$ after the initial operation. Necropsy did not reveal a direct cause, so most probably death was anesthesia related. A small dose of $0.4 \mathrm{ml}$ PVA/CMC gel was enough to provide a significant adhesion reduction. 
In experiment 2, $0.4 \mathrm{ml}$ PVA/CMC again showed adhesion reduction, where icodextrin $4 \%$ failed to diminish adhesion formation confirming the results of van't Riet et al. [28]. In contrast to the present study, Verco et al. [11] did show efficacy of Adept ${ }^{\circledR}$ in a rabbit model. As mentioned earlier, icodextrin $4 \%$ is metabolized by $\alpha$-amylase, which is present in higher amounts in the rat compared to the rabbit. This may result in an accelerated metabolizing process leading to absorption of icodextrin $4 \%$ within the first 7 days, which are critical in adhesion formation [11].

In the first two experiments, remains of PVA/CMC gel were seen in the abdominal wall during histological examination. The aim of the third experiment was to investigate the microscopic presence of anti-adhesives after 4 and 6 weeks. Presence after more than 6 weeks might be undesirable because of foreign body reaction. Nevertheless, residues of icodextrin $4 \%$ were not found in any of the three experiments, suggesting complete absorption within 2 weeks. Additionally, no PVA/CMC was observed after 4 and 6 weeks, comparable to the absorption time of 3-4 weeks found in the study by Lang et al. [7], and neoperitoneum was formed in all cases.

In conclusion, the present study shows that the new PVA/CMC gel A-Part ${ }^{\circledR}$ appears to be a safe and effective adhesion reduction agent for peroperative intra-abdominal use in the rat. These and earlier promising results have resulted in a clinical safety trial assembling the next step to clinical efficacy studies [29].

\section{Disclosure Statement}

The authors have no conflicts interest to disclose. This experiment was financially supported by B. Braun Aesculap AG, Tuttlingen, Germany. The manufacturer of the PVA/CMC hydrogel was not involved in the study design, analysis of results or preparation of the manuscript.

\section{References}

$\checkmark 1$ Menzies D, Ellis H: Intestinal obstruction from adhesions - how big is the problem? Ann R Coll Surg Engl 1990;72:60-63.

2 Menzies D: Peritoneal adhesions. Incidence, cause, and prevention. Surg Annu, 1992;24: 27-45.

3 Parker MC, Ellis H, Moran BJ, et al: Postoperative adhesions: ten-year follow-up of 12,584 patients undergoing lower abdominal surgery. Dis Colon Rectum 2001;44:822830.

4 Menzies D, Parker M, Hoare R, Knight A: Small bowel obstruction due to postoperative adhesions: treatment patterns and associated costs in 110 hospital admissions. Ann R Coll Surg Engl 2001;83:40-46.

5 Tingstedt B, Isaksson J, Andersson R: Longterm follow-up and cost analysis following surgery for small bowel obstruction caused by intra-abdominal adhesions. Br J Surg 2007;94:743-748

-6 Schnüriger B, Barmparas G, Branco BC, et al: Prevention of postoperative peritoneal adhesions: a review of the literature. Am J Surg 2011;201:111-121.

7 Lang RA, Grüntzig PM, Weisgerber C, et al: Polyvinyl alcohol gel prevents abdominal adhesion formation in a rabbit model. Fertil Steril 2007;88(suppl):1180-1186.

8 Müller SA, Weis C, Odermatt EK, et al: A hydrogel for adhesion prevention: characterization and efficacy study in a rabbit uterus model. Eur J Obstet Gynecol Reprod Biol 2010;158:67-71.
9 Weis C, Odermatt EK: A-Part ${ }^{\circledR}$ gel - an efficient adhesion prevention barrier. J Biomed Mater Res B Appl Biomater 2007;82:174-182.

10 Brown CB, Luciano AA, Martin D, et al, Adept Adhesion Reduction Study Group: Adept $^{\circledR}$ (icodextrin $4 \%$ solution) reduces adhesions after laparoscopic surgery for adhesiolysis: a double-blind, randomized, controlled study. Fertil Steril 2007;88:14131426.

11 Verco SJ, Peers EM, Brown CB, et al: Development of a novel glucose polymer solution (icodextrin) for adhesion prevention: preclinical studies. Hum Reprod 2000;15:17641772.

12 Wiseman DM, Trout JR, Diamond MP: The rates of adhesion development and the effects of crystalloid solutions on adhesion development in pelvic surgery. Fertil Steril 1998;70:702-711.

13 Zühlke HV, Lorenz EM, Straub EM, Savvas V: Pathophysiology and classification of adhesions (in German). Langenbecks Arch Chir Suppl II Verh Dtsch Ges Chir 1990: 1009-1016.

14 Hooker GD, Taylor BM, Driman DK: Prevention of adhesion formation with use of sodium hyaluronate-based bioresorbable membrane in a rat model of ventral hernia repair with polypropylene mesh - a randomized, controlled study. Surgery 1999;125: 211-216.
15 Van den Tol P, ten Raa S, van Grevenstein $\mathrm{H}$ et al: Icodextrin reduces postoperative adhesion formation in rats without affecting peritoneal metastasis. Surgery 2005; 137:348354.

16 Van der Wal, JB, Jeekel J: Biology of the peritoneum in normal homeostasis and after surgical trauma. Colorectal Dis 2007;9(suppl 2):9-13.

17 Luijendijk RW, de Lange DC, Wauters CC, et al: Foreign material in postoperative adhesions. Ann Surg 1996;223:242-248.

18 Bhardwaj R, Parker MC: Impact of adhesions in colorectal surgery. Colorectal Dis 2007; 9(suppl 2):45-53.

19 Metwally M, Watson A, Lilford R, Vandekerckhove P: Fluid and pharmacological agents for adhesion prevention after gynaecological surgery. Cochrane Database Syst Rev 2006:CD001298.

$\checkmark 20$ Beck DE, Cohen Z, Fleshman JW, et al, Adhesion Study Group Steering Committee: A prospective, randomized, multicenter, controlled study of the safety of Seprafilm adhesion barrier in abdominopelvic surgery of the intestine. Dis Colon Rectum 2003;46: 1310-1319.

21 Fazio VW, Cohen Z, Fleshman JW, et al: Reduction in adhesive small-bowel obstruction by Seprafilm adhesion barrier after intestinal resection. Dis Colon Rectum 2006;49:111. 
22 Mettler L, Audebert A, Lehmann-Willenbrock E, et al: A randomized, prospective, controlled, multicenter clinical trial of a sprayable, site-specific adhesion barrier system in patients undergoing myomectomy. Fertil Steril 2004;82:398-404.

-23 Sawada T, Nishizawa H, Nishio E, Kadowaki M.: Postoperative adhesion prevention with an oxidized regenerated cellulose adhesion barrier in infertile women. J Reprod Med 2000;45:387-389.
24 Vrijland WW, Tseng LN, Eijkman HJ, et al: Fewer intraperitoneal adhesions with use of hyaluronic acid-carboxymethylcellulose membrane: a randomized clinical trial. Ann Surg 2002;235:193-199.

25 Wiseman DM, Gottlick-Iarkowski L, Kamp L: Effect of different barriers of oxidized regenerated cellulose on cecal and side wall adhesions in the presence and absence of bleeding. J Invest Surg 1999;12:141-146.

26 Van der Wal JB, Iordens GI, Vrijland WW, et al: Adhesion prevention during laparotomy: long-term follow-up of a randomized clinical trial. Ann Surg 2011;253:1118-1121.

27 Metwally M, Cheong Y, Li TC: A review of techniques for adhesion prevention after gynaecological surgery. Curr Opin Obstet Gynecol 2008;20:345-352.
28 Van't Riet M, de Vos van Steenwijk PJ, et al: Prevention of adhesion to prosthetic mesh: comparison of different barriers using an incisional hernia model. Ann Surg 2003;237: 123-128.

29 Lang R, Baumann P, Jauch KW, et al: A prospective, randomised, controlled, doubleblind phase I-II clinical trial on the safety of A-Part ${ }^{\circledR}$ gel as adhesion prophylaxis after major abdominal surgery versus non-treated group. BMC Surg 2010;10:20. 